\title{
Direct Detection of Circulating Hepatitis C Virus RNA Using Probes from the $5^{\prime}$ Untranslated Region
}

Ke-Qin Hu, Chang-Hong Yu, and John M. Vierling

Departments of Medicine, Cedars-Sinai Medical Center and University of California, Los Angeles, School of Medicine, Los Angeles, California 90048

A portion of this work has been published in abstract form (1991. Hepatology. 14:118A)

Address correspondence to John M. Vierling, M.D., Hepatology, Suite 7511, Cedars-Sinai Medical Center, 8700 Beverly Boulevard, Los Angeles, CA 90048.

Received for publication 22 November 1991 and in revised form 18 February 1992.

\footnotetext{
J. Clin. Invest.

(c) The American Society for Clinical Investigation, Inc.

$0021-9738 / 92 / 06 / 2040 / 06 \$ 2.00$

Volume 89, June 1992, 2040-2045
}

\begin{abstract}
Diagnostic testing for hepatitis $\mathrm{C}$ virus (HCV) infection currently is based on the presence of anti-HCV antibodies or a positive HCV RNA polymerase chain reaction (PCR) test. Although HCV RNA PCR is a sensitive and specific technique, widespread application is limited. Moreover, HCV RNA PCR is subject to false-positive reactions through contamination and is inherently difficult to standardize and quantitate. To overcome limitations of HCV RNA PCR, we produced both CDNA and riboprobes from a 241 nucleotide sequence of the $5^{\prime}$ untranslated region of the HCV genome for slot hybridization. Hybridization was absent using normal human serum, horse serum, or hepatic cellular RNA from noninfected liver. Hybridization occurred predominantly with positive-stranded $\mathrm{HCV}$ RNA and was abolished by pretreatment with RNase A. Slot hybridization was performed on serum samples from 60 patients with chronic HCV infection and a positive HCV RNA PCR and 20 patients with liver diseases unrelated to $H C V$ who had a negative HCV RNA PCR. Slot hybridization with cDNA and riboprobes showed concordance with HCV RNA PCR of 95 and $98.3 \%$, respectively. There were no false-positive reactions in controls. The sensitivity of riboprobe hybridization was comparable to that of one stage HCV RNA PCR using $5^{\prime}$ untranslated region primers. Riboprobe hybridization with the HCV H strain standard was positive in the dilution corresponding to $10^{-6}$ chimpanzee infectious doses $_{50} / \mathrm{ml}$. The density of the hybridization signals correlated significantly with the mass of an RNA standard extracted from the liver of a patient with HCV infection. The relative quantities of HCV RNA in the sera of selected patients varied and were not correlated with the duration of disease or the histopathological stage. The highest relative quantities were associated with concurrent immunosuppression. We conclude that slot hybridization is a sensitive, specific alternative to HCV RNA PCR that can be directly quantitated using appropriate HCV RNA standards. (J. Clin.
\end{abstract}

Invest. 1992. 89:2040-2045.) Key words: hepatitis C virus (HCV) RNA polymerase chain reaction $\bullet$ HCV CDNA $\bullet$ HCV riboprobe • RNA slot hybridization • Northern blot assay

\section{Introduction}

Hepatitis $\mathrm{C}$ virus (HCV), ${ }^{1}$ the principal agent of non-A, non-B (NANB) viral hepatitis (1-3), was recently identified by a recombinant complementary DNA (cDNA) approach (4). Prospective studies of sentinel counties in the United States indicate that $\sim 150,000$ new cases of non-A, non-B viral hepatitis/ $\mathrm{HCV}$ infection occur yearly, and that $\geq 50 \%$ become chronic (5). Severe chronic sequelae include decompensated cirrhosis, which may necessitate liver transplantation, and hepatocellular carcinoma $(1-3,6)$.

HCV is an RNA virus related to human flaviviruses and animal pestiviruses $(7,8)$. The positive-stranded RNA genome of HCV consists of $\sim 10,000$ nucleotides $(n t)$. This sequence contains a single open reading frame capable of encoding a 3,100 amino acid polyprotein precursor from which individual structural and nonstructural proteins are produced (9-11). Approximately 324-341 nt at the $5^{\prime}$ end of the open reading frame are unassociated with protein synthesis and, thus, are referred to as the $5^{\prime}$ untranslated region ( $5^{\prime}$ UTR) (9-12). Comparison of reported $\mathrm{HCV}$ nt sequences demonstrates variations in the structural and nonstructural regions among different $\mathrm{HCV}$ strains ranging from 9 to $26 \%$. In contrast, the nt sequences of the $5^{\prime}$ UTR are $\geq 97 \%$ homologous among different strains (8, $13,14)$.

Two major techniques are currently used to detect HCV infection. The first technique detects antibody produced in response to HCV infection (anti-HCV) $(1,2,15)$. This technique is associated with both false-positive and -negative reactions (15-17). Furthermore, multiple weeks are required for development of anti-HCV after HCV infection (18), which precludes the use of anti-HCV for the diagnosis of acute infection. The second technique detects HCV RNA through a reverse transcription and polymerase chain reaction (HCV RNA PCR) (19-21). Although HCV RNA PCR is a sensitive technique, extensive application is limited by cost, labor intensity, risk of false-positive results through contamination $(22,23)$, and disparate results among laboratories using different primers $(21,24)$. Variation in the efficiency of reverse transcription of HCV RNA and amplification of cDNA also makes quantitation and

1. Abbreviations used in this paper: $\mathrm{CID}_{50}$, chimpanzee infectious doses $_{50} ; \mathrm{HCV}$, hepatitis $\mathrm{C}$ virus; nt, nucleotide; $\mathrm{PCR}$, polymerase chain reaction; UTR, untranslated region. 
standardization of HCV RNA PCR inherently difficult (25-28).

To overcome the limitations of current techniques for detection of HCV infection, it is desirable to develop a test which is sensitive, specific, quantitative, affordable, and suitable for testing large populations of patients or blood donors. Although direct hybridization fulfills these criteria, it has been assumed that the quantity of circulating HCV RNA is insufficient for this technique $(8,15)$. In contrast, our results indicate that probes from the highly conserved $5^{\prime} \operatorname{UTR}(8,13,14)$ can be used for direct detection of HCV RNA using slot hybridization.

\section{Methods}

HCV RNA PCR. The guanidinium isothiocyanate-acid-phenol technique (29) was used to extract RNA from 0.4-0.5-ml aliquots of serum HCV RNA PCR was performed as previously reported $(12,30)$. Oligonucleotide primers (5'-ACTCCACCATAGATCATCCC-3', 7-26 nt, sense; 5'-AACACTACTCGGCTAGCAGT-3', 229-248 nt, antisense) from the HCV 5' UTR were synthesized (12) for HCV RNA PCR. Specific PCR products of 241 bp were identified by agarose electrophoresis, ethidium bromide staining, and Southern blot hybridization using ${ }^{32} \mathrm{P}$-labeled primers as probes $(19,28,30)$. Since results for one stage and two stage (nested) HCV RNA PCR were comparable using our 5' UTR primers (30), a one stage, 30 cycle HCV RNA PCR was used.

Construction of $H C V$ cDNA plasmid. To construct a plasmid vector containing 5' UTR HCV cDNA, the HCV RNA PCR product was purified and blunted using T4 DNA polymerase. The fragment was cloned into the Smal I site of the plasmid vector pGEM-3Z (Promega Corp., Madison, WI), using standard methods (31). Positive clones were screened by restriction digestion and hybridization after transformation. A positive clone, referred to as pGHCV1A (Fig. 1), contained a 241-nt HCV 5' UTR fragment and was used to synthesize HCV probes for slot hybridization.

DNA sequencing. DNA sequencing was performed to determine the degree of homology of the cloned HCV sequences in pGHCV1A with reported HCV sequences. Plasmid DNA was extracted using a cesium chloride gradient method (31). A DNA sequencing kit was purchased from U. S. Biochemical Corp., Cleveland, OH, and SP6 and T7 primers were obtained from Promega Corp. Sequencing was performed according to the manufacturer's instructions.

Labeling of probes. After restriction digestion, the cloned HCV cDNA fragment in pGHCV1A was recovered from the agarose gel (31). $\left.{ }^{32} \mathrm{P}\right] \mathrm{dCTP}$ was incorporated into the $\mathrm{HCV}$ cDNA probe through either nick translation or random primer DNA labeling (31) ${ }^{32} \mathrm{P}$-labeled riboprobes were synthesized in vitro from the HCV $5^{\prime}$ UTR CDNA template in pGHCV1A using an RNA polymerase reaction to incorporate [ ${ }^{32}$ P]UTP (31-33). The DNA template was then degraded through DNase I digestion. As shown in Fig. 1, SP6 and T7 RNA polymerases synthesize $\mathrm{HCV}$ riboprobes with sense and antisense orientation, re-

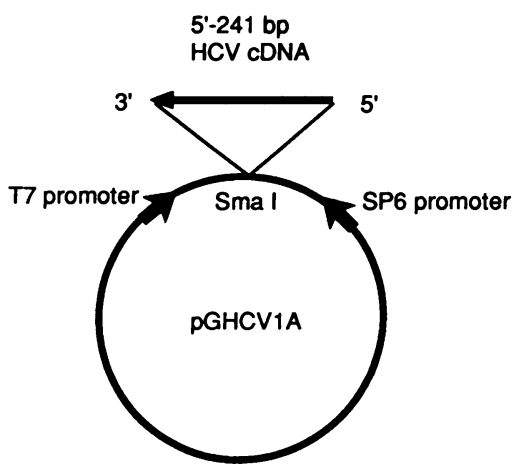

Figure 1. Construction of plasmid pGHCV1A. A 241-bp cDNA product of HCV RNA PCR from the $5^{\prime}$ UTR of HCV genome was inserted into Smal I site of the vector pGEM-3Z. The orientation of the insertion is indicated by the $3^{\prime}$ and $5^{\prime}$ designation. spectively. Labeled probes were further purified by Sephadex G50 column chromatography (31).

Hybridization assays. RNA, extracted from serum using the guanidinium isothiocyanate-acid-phenol technique (29), was loaded onto Nytran membranes (Schleicher \& Schuell Inc., Keene, NH). Blotted membranes were prehybridized for $3-4 \mathrm{~h}$ at $60-65^{\circ} \mathrm{C}$ and then hybridized with either a ${ }^{32} \mathrm{P}$-labeled HCV cDNA probe or riboprobe at 60 $65^{\circ} \mathrm{C}$ for $20-24 \mathrm{~h}$ (31). After washing, the membranes were exposed to $\mathrm{x}$-ray film (Kodak, Rochester, NY) at $-70^{\circ} \mathrm{C}$ for $24-48 \mathrm{~h}$.

Extensive specificity controls for slot hybridization were performed. Normal human serum, horse serum, and a hepatic cellular RNA extract from a patient with alpha-1-antitrypsin deficiency were used as negative controls. To determine the RNA specificity of the slot reaction, RNA isolated from the serum of $\mathrm{HCV}$-infected individuals was pretreated with RNase $A(1 \mu \mathrm{g} / \mu \mathrm{l})$ at $37^{\circ} \mathrm{C}$ for $30 \mathrm{~min}$ and then hybridized with either HCV cDNA probes or riboprobes, as described above. Since the positive-stranded HCV genome was expected to predominate in the serum of infected individuals, $\mathrm{HCV}$ riboprobes with sense and antisense orientation were compared. Northern blot assays (31) were performed to identify the molecular size of HCV RNA present in positive serum samples, using a ${ }^{32} \mathrm{P}$-labeled $\mathrm{HCV}$ riboprobe with antisense orientation. RNA extracted from the liver of a patient with $\mathrm{HCV}$ infection and an HCV H strain (34) serum standard (a kind gift of Dr. Harvey Alter, National Institutes of Health) were used to evaluate the sensitivity of slot hybridization.

Quantitative analysis. Hepatic cellular RNA from an HCV-infected patient was used as a standard to quantitate: (a) the sensitivity of HCV RNA PCR (one stage, 30 cycles) and riboprobe slot hybridization, and $(b)$ the relative amount of HCV RNA in the sera of selected patients. Northern blots demonstrated that the hepatic cellular RNA contained HCV viral RNA. The riboprobe hybridization signals were measured with a computerized densitometer (Helena Laboratories, Beaumont, TX). The correlation between the density and the mass of hepatic cellular RNA was analyzed by linear regression to construct a standard curve. The relative quantity of HCV RNA in the sera of selected patients was calculated from the linear regression equation.

Patients. 60 patients with putative chronic HCV infection were included in this study. Diagnosis of HCV infection was based on exclusion of other etiologies for chronic liver disease and a positive HCV RNA PCR. One patient had evidence of concurrent chronic HCV and hepatitis B virus infection. 20 patients with acute and chronic liver diseases of other etiologies were studied as negative controls. In each control patient, the HCV RNA PCR was negative. The diagnoses in the control group included: acute hepatitis A $(n=2)$, chronic hepatitis B $(n$ $=6)$, chronic hepatitis $\mathrm{B}$ and $\mathrm{D}(n=1)$, chronic autoimmune hepatitis type $1(n=2)$, primary biliary cirrhosis $(n=1)$, Wilson's disease $(n=1)$, secondary biliary cirrhosis $(n=1)$, alcoholic hepatitis and/or cirrhosis $(n=4)$, cryptogenic cirrhosis $(n=1)$, and steatonecrosis secondary to obesity and hyperlipoproteinemia $(n=1)$. All serum samples were stored at $-70^{\circ} \mathrm{C}$ before use.

\section{Results}

Specificity of $c D N A$ and riboprobes. DNA sequencing showed that the 241-bp cDNA sequence in pGHCV1A was $100 \%$ homologous with the sequence of HC-J1 (12), and differed by 4 bp from the sequence of HCV-1 (10). Thus, the cDNA and riboprobes used for slot hybridization were specific for HCV.

Results of control studies also indicated that the probes were highly specific for HCV RNA. RNA extracted from normal human serum, horse serum, and the liver of a patient with alpha-1-antitrypsin deficiency did not produce hybridization signals with either HCV cDNA or riboprobes (data not shown). As shown in Fig. $2 A$, hybridization signals were abolished by pretreatment of RNA extracted from HCV-positive serum with RNase A, indicating that the HCV cDNA probe specifi- 
A

A1

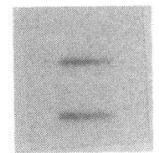

B

B1

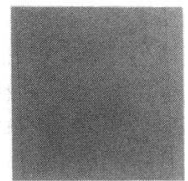

A2

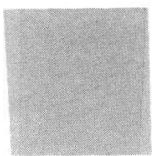

Figure 2. Specificity of HCV RNA slot assays. RNA was extracted from aliquots of 0.4-0.5 $\mathrm{ml}$ of sera from patients with chronic $\mathrm{HCV}$ infection and a positive HCV RNA PCR test. Serum RNA was hybridized with ${ }^{32} \mathrm{P}$-labeled HCV 5' UTR probes. $(A)$ Hybridization with CDNA probe before $(A I)$ and after (A2) treatment with RNase A $(n=2)$. (B) Hybridization with sense $(B I)$ and antisense (B2) riboprobes $(n=3)$.

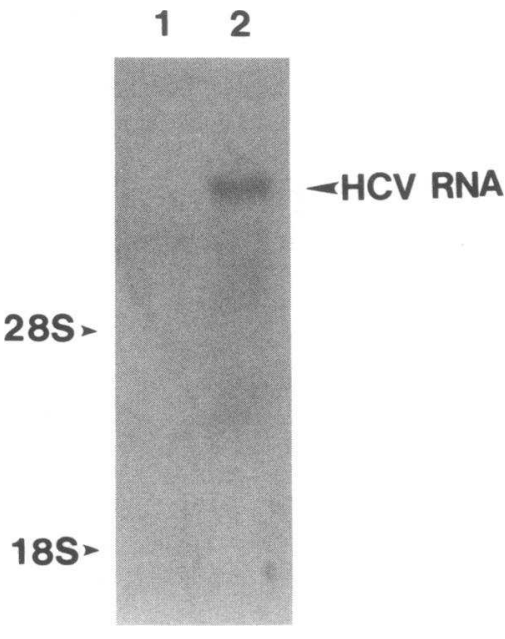

Figure 3. Northern blot assays of HCV RNA. RNA extracted from $1.5-\mathrm{ml}$ aliquots of serum from a normal individual (lane 1) and a patient with chronic $\mathrm{HCV}$ infection and a positive HCV RNA PCR test (lane 2) were blotted and hybridized with an antisense ${ }^{32} \mathrm{P}$-labeled riboprobe from the $5^{\prime}$ UTR of the HCV genome. Both $18 \mathrm{~S}$ and 28S rRNAs were indicated as molecular markers. A hybridization band of $\sim 10$ kilonucleotides was observed in association with chronic $\mathrm{HCV}$ infection.

cally hybridized with RNA. Since the major circulating form of HCV should contain positive-stranded viral RNA, hybridization with an $\mathrm{HCV}$ antisense riboprobe would be expected to predominate. Hybridization of three consecutive HCV-infected serum samples, using both sense and antisense riboprobes, showed hybridization signals exclusively with the antisense HCV riboprobe (Fig. $2 \mathrm{~B}$ ). Subsequent analysis of additional sera showed occasional concurrent hybridization with the sense riboprobe, indicating the presence of circulating $\mathrm{HCV}$ replicative intermediates. In each instance, the hybridization signal was less intense for the sense riboprobe than the antisense riboprobe ( $\mathrm{Hu}, \mathrm{K} .-\mathrm{Q}$., et al., unpublished observation).

To assess the molecular size of HCV RNA detected by our HCV probes, Northern blots were performed using RNA extracted from the serum of a normal control and a patient with chronic HCV infection. Hybridization with the HCV antisense riboprobe produced a signal exclusively with the patient's RNA (Fig. 3); the signal of $\sim 10 \mathrm{~kb}$ is consistent with the size of the HCV genome (9-11).

Specificity, sensitivity, and relative quantitation of $\mathrm{HCV}$ RNA slot hybridization. Table I shows the concordance of HCV RNA PCR and slot hybridization using either HCV cDNA or antisense riboprobes. HCV RNA PCR (one stage, 30 cycles) and HCV slot hybridization were performed simultaneously. A concordance of $95 \%$ was achieved between cDNA slot hybridization and HCV RNA PCR (Table I). No false positive reactions occurred in the control group. Results with the antisense riboprobe were more sensitive than those with the cDNA probe, in accord with evidence that riboprobes are superior for hybridization with RNA (31-33). A concordance of 98.3\% was present between riboprobe hybridization and HCV RNA PCR (Table I). The single patient with a positive HCV RNA PCR and negative riboprobe hybridization was the individual with concurrent hepatitis $B$ virus and $H C V$ infection. Despite increased sensitivity with the riboprobe, there were no false-positive reactions in the control group. Thus, slot hybridization using probes from HCV $5^{\prime}$ UTR is a specific method for detecting serum HCV RNA.

Both the HCV RNA PCR and riboprobe slot hybridization detected comparable amounts of HCV RNA in the extract of hepatic cellular RNA from a patient with HCV infection (Fig. 4). In a standard curve constructed to quantitate HCV RNA in patients' sera, the correlation between the density of the hybridization signals and the mass of hepatic RNA was statistically significant $(r=0.98, P<0.003)$. The relative quantities of HCV RNA in the sera of patients (Table II) varied. However, all values were within the range of the standard curve. The relative quantities of HCV RNA did not correlate with the known duration of disease or the histopathological lesion (Table II). However, the highest relative quantities were observed in patients with concurrent immunosuppression. Using the HCV H strain (34) as another relative standard, the riboprobe slot assay repeatedly detected HCV RNA at a dilution corresponding to $10^{-6}$ chimpanzee infectious doses $_{50}\left(\mathrm{CID}_{50}\right) / \mathrm{ml}$. Again the density of the hybridization signals paralleled the titer of the $\mathrm{H}$ strain dilution.

\section{Discussion}

Currently, commercial anti-HCV and investigational HCV RNA PCR are used for diagnostic HCV testing. The diagnostic utility of first generation anti-HCV tests has been limited by both false-positive and -negative results (15-17). In addition, the time required for development of detectable anti-HCV after infection makes these tests unsuitable for the diagnosis of acute HCV infection (18). Second generation anti-HCV tests, which detect antibodies reactive with several antigenic $\mathrm{HCV}$

Table I. Concordance of HCV RNA PCR and Slot Hybridization

\begin{tabular}{lccccc}
\hline & & & \multicolumn{2}{c}{ Slot hybridization assays } \\
\cline { 4 - 5 } \multicolumn{1}{c}{ Groups } & $n$ & HCV PCR & cDNA probe & Riboprobe \\
\hline HCV patients & 60 & $60(100.0 \%)$ & $57(95.0 \%)$ & $59(98.3 \%)$ \\
Negative controls & 20 & $0(0.0 \%)$ & $0(0.0 \%)$ & $0(0.0 \%)$ \\
\hline
\end{tabular}




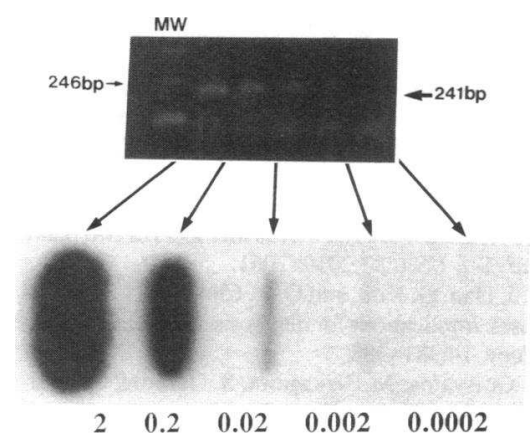

$\begin{aligned} & \text { HCV PCR } \\ & \text { (one stage) }\end{aligned}$
$\begin{aligned} & \text { HCV Slot } \\ & \text { (riboprobe) }\end{aligned}$
$\begin{aligned} & \text { Amount of Hepatic } \\ & \text { Cellular RNA }(\mu \mathrm{g})\end{aligned}$

Figure 4. Comparison of the sensitivity of HCV riboprobe slot assays and HCV RNA PCR. Serial dilutions of RNA extracted from the liver of a patient with chronic $\mathrm{HCV}$ infection were tested concurrently with one stage HCV PCR (30 cycles) and riboprobe slot hybridization. Molecular weight was indicated by a 123-bp ladder DNA marker from Bethesda Research Laboratories/GIBCO, Gaithersburg, MD. (HCV PCR) The small arrow (left) shows a molecular weight marker of $246 \mathrm{bp}$. The large arrow (right) shows the 5' 241-bp product of the HCV RNA PCR. (HCV Slot) The density of the hybridization signals was directly proportional to the quantity of hepatic cellular RNA. Both the HCV RNA PCR and riboprobe slot hybridization detected comparable amounts of HCV RNA in the extract of hepatic cellular RNA.

proteins, increase both sensitivity and specificity (17). Although the time required for the development of $\mathrm{HCV}$-specific antibodies after acute infection is reduced, these tests remain unsatisfactory for the diagnosis of acute infection. HCV RNA $\mathrm{PCR}$, performed in individual research laboratories, has rapidly become the diagnostic standard for HCV infection (19-21, 24-29). Most investigators prefer primers from the $5^{\prime}$ UTR since HCV nt analyses have indicated that the $5^{\prime}$ UTR has a very high homology $(\geq 97 \%)$ among different HCV strains $(8$, $13,14)$. In addition, HCV RNA PCR using $5^{\prime}$ UTR primers is more sensitive than HCV RNA PCR using primers from either the NS3 or NS4 regions $(24,30)$. Available data indicate that HCV RNA PCR can detect circulating HCV RNA before the onset of aminotransferase elevations in acute $\mathrm{HCV}$ infection (18) and can be used to assess the viral response to recombinant interferon therapy (35). Despite these advantages, PCR testing for HCV RNA also has multiple limitations including cost, labor intensity, liability for false-positive results $(22,23)$, disparate results with different primers $(21,24,30)$, and problematic quantitation and standardization (25-28).

The results of the present study demonstrate that slot hybridization with riboprobes from the $5^{\prime}$ UTR of the HCV genome is a sensitive, specific, and quantitative technique for the detection of circulating HCV RNA. In addition, this technique obviates the problem of contamination that can yield falsepositive results in HCV RNA PCR. Contrary to the assumption that the quantity of circulating $\mathrm{HCV}$ is insufficient for direct hybridization $(8,15)$, HCV RNA was readily detected using either cDNA or riboprobes shown to be specific for a 241-nt sequence of the $5^{\prime}$ UTR. These results suggest that the quantity of circulating HCV RNA may be underestimated by titers based on infectious dose units $(8,15)$. Concordance between HCV RNA PCR and slot hybridization was excellent. No false positive results were observed among control patients with a variety of other acute and chronic liver diseases, including acute viral hepatitis $\mathrm{A}$, chronic hepatitis $\mathrm{B}$, and chronic
Table II. Relative Quantitation of Serum HCV RNA in Selected Patients

\begin{tabular}{rlccc}
\hline Patient & Diagnosis & Duration & Immunosuppression & $\begin{array}{c}\text { Relative HCV } \\
\text { RNA }^{\ddagger}\end{array}$ \\
\hline & & $y r$ & & \\
1 & Anti-HCV+, & $?$ & 0 & 0.038 \\
& $\begin{array}{c}\text { blood donor } \\
2\end{array}$ & & & \\
& Anti-HCV+, & $?$ & 0 & 0.019 \\
3 & blood donor & & & \\
4 & CAH & 19 & 0 & 0.081 \\
5 & CAH & 5 & 0 & 0.020 \\
6 & CAH/Cirrhosis & 25 & 0 & 0.097 \\
7 & CAH & 10 & 0 & 0.124 \\
8 & CAH/Cirrhosis & 4 & 0 & 0.092 \\
9 & CAH & 2 & 0 & 0.069 \\
10 & CPH & 5 & 0 & 0.018 \\
11 & CAH & 3 & 0 & 0.017 \\
12 & CAH & 9 & 0 & 0.042 \\
13 & Hepatitis C, & 0.6 & + & 0.011 \\
& post OLT & & & 0.132 \\
14 & Hepatitis C, & 0.6 & + & \\
& post OLT & & & 0.198 \\
15 & Hepatitis C, & 0.6 & + & 0.850 \\
& post OLT & & & \\
& & & & \\
& & &
\end{tabular}

* Patients 1 and 2 had elevated serum aminotransferase levels but were not biopsied. All other patients had liver biopsies. $\mathrm{CAH}$, chronic active hepatitis; CPH, chronic persistent hepatitis; OLT, orthotopic liver transplantation. ${ }^{\ddagger} \mu \mathrm{g}$ RNA calculated from a standard curve of the riboprobe hybridization signal density and the mass of RNA extracted from an HCV-infected liver (see text for details). There was no significant correlation between the relative HCV RNA and either the known duration of disease $(r=0.448, P=0.1947)$ or the histopathological lesion $(r=0.234, P=0.5157)$ in nonimmunosuppressed patients.

hepatitis B and D. The single patient with a positive HCV RNA PCR and negative riboprobe slot blot had evidence of both hepatitis $B$ virus and HCV infection. The effect of concurrent infection with $\mathrm{HCV}$ and other hepatitis viruses on the sensitivity of the riboprobe assay remains undefined.

In addition to a high concordance with the HCV RNA PCR, several lines of evidence indicated that the slot hybridization assay was highly specific for HCV. The absence of hybridization with normal human serum, horse serum, and hepatic cellular RNA from a patient with alpha-1-antitrypsin deficiency excluded nonspecific binding of the probes. Hybridization was specific for RNA, as shown by abolishment with RNase A pretreatment. Hybridization was uniformly observed with the antisense riboprobe, reacting with circulating positivestranded HCV RNA. Occasionally, concurrent hybridization was observed with the sense riboprobe, indicating the presence of circulating replicative intermediates ( $\mathrm{Hu}, \mathrm{K}$.-Q., et al., unpublished observation). These results are consistent with a recent report of circulating replicative intermediates detected by HCV RNA PCR (36). Finally, Northern blot analysis of an HCV-infected serum with the antisense riboprobe showed a hybridization signal of the same size as the HCV genome $(\sim 10 \mathrm{~kb})$. 
Since the quantity of infectious $\mathrm{HCV}$ in the circulation appears to be very low during $\mathrm{HCV}$ infection $(8,15)$, the sensitivity of any technique to detect the HCV genome is critically important. Our data clearly indicate that the sensitivity of HCV RNA slot hybridization using a riboprobe is comparable to that of a one stage HCV RNA PCR using primers from the $5^{\prime}$ UTR. Riboprobe hybridization with RNA isolated from the HCV H strain standard showed reactivity with a dilution corresponding to $10^{-6} \mathrm{CID}_{50} / \mathrm{ml}$. Recent reports of HCV RNA PCR using the same $\mathrm{H}$ strain standard have shown variable sensitivity, detecting dilutions ranging from $10^{-1}$ to $10^{-7} \mathrm{CID}_{50} / \mathrm{ml}(21$, 24). Thus, the sensitivity of riboprobe hybridization falls within the range reported for HCV RNA PCR $(21,24)$. Based on evidence that the average infectivity titer of infectious human plasma is $10^{-2}$ to $10^{-4} \mathrm{CID}_{50} / \mathrm{ml}$ (37), riboprobe hybridization would be expected to identify infectious carriers. Regardless of the precise sensitivity, the high concordance of the riboprobe hybridization and HCV RNA PCR indicates an appropriate sensitivity for clinical application.

The ability to quantitate $\mathrm{HCV}$ in blood or tissues would greatly facilitate understanding of the natural history of $\mathrm{HCV}$ infection and the effect of current or future antiviral therapies. Recently, individual groups have reported progress in quantitative HCV RNA PCR (25-28), but it remains to be determined if quantitative HCV RNA PCR can be adapted for widespread use among investigators using different PCR protocols and primers. In contrast, slot hybridization is suitable for direct quantitation of HCV RNA by densitometry. Using hepatic RNA from an HCV-infected liver as a standard, the density of the riboprobe hybridizing signals and the dilution of the hepatic standard were significantly correlated. Similar results were obtained with the $\mathrm{H}$ strain $\mathrm{HCV}$ standard. The relative quantities of HCV RNA calculated from the hepatic RNA standard varied among selected patients. The quantity was not correlated with the duration of disease or the histopathological stage in this cohort. The highest quantities were associated with concurrent immunosuppression. This observation suggests that immunosuppression may augment $\mathrm{HCV}$ replication either by a direct effect on the virus or by diminishing the host immune response against the virus. Overall, the data indicate that quantitation in mass units or genomic units should be possible when sufficient amounts of specific HCV RNA standards become available.

\section{Acknowledgments}

This work was supported by an institutional grant from Cedars-Sinai Medical Center.

\section{References}

1. Kuo, G., Q.-L. Choo, H. J. Alter, G. L. Gitnick, A. G. Redeker, R. H. Purcell, T. Miyamura, J. L. Dienstag, M. J. Alter, C. E. Stevens, et al. 1989. An assay for circulating antibodies to a major etiologic virus of human non-A, non-B hepatitis. Science (Wash. DC). 244:362-364.

2. Alter, H. J., R. H. Purcell, J. W. Shih, J. C. Melpolder, M. Houghton, Q.-L. Choo, and G. Kuo. 1989. Detection of antibody to hepatitis $C$ virus in prospectively followed transfusion recipients with acute and chronic non-A, non-B hepatitis. N. Engl. J. Med. 321:1494-1500.

3. Katkov, W. N., J. L. Dienstag, H. Cody, A. A. Evans, Q.-L. Choo, M. Houghton, and G. Kuo. 1991. Role of hepatitis C virus in non-B chronic liver disease. Arch. Intern. Med. 151:1548-1552.

4. Choo, Q.-L., G. Guo, A. J. Weiner, L. R. Overby, D. W. Bradley, and M. Houghton. 1989. Isolation of a cDNA clone derived from a blood-borne non-A, non-B hepatitis genome. Science (Wash. DC). 244:359-362.
5. Alter, M. J., and R. E. Sampliner. 1989. Hepatitis C: and miles to go before we sleep. $N$. Engl. J. Med. (editorial). 321:1538-1540.

6. Saito, I., T. Miyamura, A. Ohbayashi, H. Harada, T. Katayama, S. Kikuchi, Y. Watanabe, S. Koi, M. Onji, Y. Ohta, et al. 1990. Hepatitis C virus infection is associated with the development of hepatocellular carcinoma. Proc. Natl. Acad. Sci. USA. 87:6547-6549.

7. Miller, R., and R. H. Purcell. 1990. Hepatitis C virus shares amino acid sequence similarity with pestivirus and flavivirus as well as members of two plant virus subgroups. Proc. Natl. Acad. Sci. USA. 87:2059-2061.

8. Houghton, M., A. Weiner, J. Han, G. Kuo, and Q.-L. Choo. 1991. Molecular biology of the hepatitis $\mathrm{C}$ viruses: implications for diagnosis, development and control of viral disease. Hepatology. 14:381-388.

9. Kato, N., M. Hijikata, Y. Ootsyama, M. Nakagawa, S. Ohkoshi, T. Sugimura, and K. Shimotohno. 1990. Molecular cloning of the human hepatitis C virus genome from Japanese patients with non-A, non-B hepatitis. Proc. Natl. Acad. Sci. USA. 87:9524-9528.

10. Choo, Q.-L., K. H. Richman, J. H. Han, K. Berger, C. Lee, C. Dong, C. Gallegos, D. Coit, A. Medina-Selby, P. J. Barr, et al. 1991. Genetic organization and diversity of the hepatitis C virus. Proc. Natl. Acad. Sci. USA. 88:2451-2455.

11. Taksmizawa, A., C. Mori, I. Fuke, S. Manabe, S. Murakami, J. Fujita, E

Onishi, T. Andoh, I. Yoshida, and H. Okayama. 1991. Structure and organization of the hepatitis $\mathrm{C}$ virus genome isolated from human carriers. J.Virol. 65:1105-1113.

12. Okamoto, H., S. Okada, Y. Sugiyama, S. Totsumoto, T. Tanaka, H. Yoshizawa, F. Tsuda, Y. Miyakawa, and M. Mayumi. 1990. The 5'-terminal sequence of the hepatitis C virus genome. Jpn. J. Exp. Med. 60:167-177.

13. Takeuchi, K., Y. Kubo, S. Boonmar, Y. Watanabe, T. Katayama, Q.-L. Choo, G. Kuo, M. Houghton, I. Saito, and T. Miyamura. 1990. The putative nucleocapsid and envelope protein genes of hepatitis $C$ virus determined by comparison of the nucleotide sequences of two isolates derived from an experimentally infected chimpanzee and healthy human carriers. J. Gen. Virol. 71:30273033.

14. Han, J. H., V. Shyamala, K. H. Richman, M. J. Brauer, B. Irvine, M. S Urder, P. Tekamp-Olson, G. Kuo, Q.-L. Choo, and M. Houghton. 1991. Characterization of the terminal regions of hepatitis $C$ viral RNA: identification of conserved sequences in the $5^{\prime}$ untranslated region and poly (A) tails at the $3^{\prime}$ end. Proc. Natl. Acad. Sci. USA. 88:1711-1715.

15. Alberti, A. 1991. Diagnosis of hepatitis C. Facts and perspectives. J. Hepatol. (Amst.). 12:279-282.

16. Gary, J. J., T. G. Wreghitt, P. J. Friend, D. G. D. Wight, V. Sundaresan and R. Y. Calne. 1990. Differentiation between specific and non-specific hepatitis $\mathrm{C}$ antibodies in chronic liver disease. Lancet. 335:609-610.

17. Aach, R. D., C. E. Stevens, F. B. Hollinger, J. W. Mosley, D. A. Peterson, P. E. Taylor, R. G. Johson, L. H. Barbosa, and G. J. Nemo. 1991. Hepatitis C virus infection in post-transfusion hepatitis: an analysis with first- and secondgeneration assays. N. Engl. J. Med. 325:1325-1329.

18. Farci, P., H. J. Alter, D. Wong, R. G. Miller, J. W. Shih, B. Jett, and R. H Purcell. 1991. A long-term study of hepatitis $C$ virus replication in non-A, non-B hepatitis. N. Engl. J. Med. 325:98-104.

19. Weiner, A. J., G. Kuo, D. W. Bradley, F. Bonino, G. Saracco, C. Lee, J. Rosenblatt, Q.-L. Choo, and M. Houghton. 1990. Detection of hepatitis C viral sequences in non-A, non-B hepatitis. Lancet. 335:1-3.

20. Garson, J. A., R. S. Tedder, M. Briggs, P. Tuke, J. A. Glazebrook, A. Trute, D. Parker, J. A. J. Barbara, M. Contreras, and S. Aloysius. 1990. Detection of hepatitis C viral sequences in blood donations by "nested" polymerase chain reaction and prediction of infectivity. Lancet. 335:1419-1422.

21. Cristiano, K., A. M. Di Bisceglie, J. H. Hoofnagle, and S. Feinstone. 1991. Hepatitis C viral RNA in serum of patients with chronic non-A, non-B hepatitis: detection by the polymerase chain reaction using multiple primers sets. Hepatology. 14:51-55.

22. Innis, M. A., D. H. Gelfand, J. J. Sininsky, and T. J. White. 1990. PCR Protocols. A Guide to Methods and Applications. Academic Press, Inc., San Diego, CA.

23. Kwok, S., and R. Higuchi. 1989. Avoiding false positive with PCR. Nature (Lond.). 339:237-238.

24. Inchauspe, G., K. Abe, S. Zebedee, M. Nasoff, and A. M. Prince. 1991. Use of conserved sequences from hepatitis $C$ virus for the detection of viral RNA in infected sera by polymerase chain reaction. Hepatology. 14:595-600.

25. Simmonds, P., L. Q. Zhang, H. G. Watson, S. Rebus, E. D. Ferguson, P. Balfe, G. H. Leadbetter, P. L. Yap, J. F. Peutherer, and C. A. Ludlam. 1990. Hepatitis $\mathrm{C}$ quantification and sequencing in blood products, haemophiliacs, and drug users. Lancet. 336:1469-1472.

26. Shindo, M., A. M. Di Bisceglie, J. Silver, T. Limjoco, J. H. Hoofnagle, and S. M. Feinstone 1991. Quantitation of hepatitis $C$ virus RNA in serum using the polymerase chain reaction and a colorimetric enzymatic detection system. Hepatology. 14:64A. (Abstr.)

27. Chung R. T. J. L. Dienstag and L. M. Kaplan. 1991. Precise quantitation of hepatitis C RNA using a competitive polymerase chain reaction: correlation of clinical course with levels of circulating RNA. Hepatology. 14:65A. (Abstr.) 
28. Ulrich, P. P., J. M. Romeo, P. K. Lane, I. Kelly, L. J. Daniel, and G. N. Vyas. 1990. Detection, semiquantitation, and genetic variation in hepatitis $C$ virus sequences amplified from the plasma of blood donors with elevated alnine aminotransferase. J. Clin. Invest. 86:1609-1614.

29. Chomczynski, P., and N. Sacchi. 1987. Single-step method of RNA isolation by acid guanidinum thiocyanate-phenol-chloroform extraction. Anal. Bio chem. 163:156-159.

30. Hu, K.-Q., C.-H. Yu, and J. M. Vierling. 1991. Comparison of HCV cDNA polymerase chain reaction (PCR) using primers from the 5 -non-coding and nonstructural regions of the HCV genome. Hepatology. 14:207A. (Abstr.)

31. Sambrook, J., E. F. Fritsch, and T. Maniatis. 1989. Molecular Cloning: A Laboratory Manual. (Second edition). Cold Spring Harbor Laboratory, Cold Spring Harbor, NY.

32. Melton, D. A., P. A. Krieg M. R. Rebagliati, T. Maniatis, K. Zinn, and M. R. Green. 1984. Efficient in vitro synthesis of biologically active RNA and RNA hybridization probes from plasmids containing a bacteriophage SP6 promoter. Nucleic Acids Res. 12:7035-7056.

33. Smedile, A., K. F. Bergmann, B. M. Baroudy, F. V. Wells, R. H. Purcell, F.
Bonino, M. Rizzetto, and J. L. Gerin. 1990. Riboprobe assay for HDV RNA: a sensitive method for the detection of the HDV genome in clinical serum samples. J. Med. Virol. 30:20-24.

34. Feinstone, S. M., H. J. Alter, H. P. Dienes, Y. Shimizu, H. Popper, D. Blackmore, D. Sly, W. T. London, and R. H. Purcell. 1981. Non-A, non-B hepatitis in chimpanzees and marmosets. J. Infect. Dis. 144:588-598.

35. Brillanti, S., J. A. Garson, P. W. Tuke, C. Ring, M. Briggs, C. Masci, M. Miglioli, L. Barbara, and R. S. Tedder. 1991. Effect of alpha-interferon therapy on hepatitis $\mathrm{C}$ viremia in community-acquired chronic non-A, non-B hepatitis: a quantitative polymerase chain reaction study. J. Med. Virol. 34:136-141.

36. Fong T.-L., M. Shindo, S. Feinstone, J. H. Hoofnagle, and A. M. Di Biscegli. 1991. Detection of replicative intermediates of hepatitis C viral RNA in liver and in serum of patients with chronic hepatitis C. J. Clin. Invest. 88:10581060.

37. Tabor, E., R. J. Gerety, J. A. Drucker, L. B. Seeff, J. H. Hoofnagle, D. R. Jackson, M. April, L. F. Barker, and G. Pineda-Tamondong. 1978. Transmission of non-A, non-B hepatitis from man to chimpanzee. Lancet. i:463-466. 